\title{
Link Performance of an CDMA-Based Time-of-Flight Ranging by Using LED Visible Light
}

\author{
Yang Wang*, Chengchao Liang*, Xin Su*, KyungHi Chang
}

\begin{abstract}
The use of ranging sensors on automobiles is becoming common with the desire of traffic safety by providing drivers the information of the relative distance between the vehicles. In this paper, the LED visible light ranging system different from the conventional ranging systems using the RF signal is investigated. For such a system, we propose a novel ranging algorithm which combines the time-of-flight (TOF) with the CDMA technology. Via the CDMA technology, the TOF ranging system can accurately distinguish the desired ranging signal from the visible light interferences of the neighbor vehicles. In addition, the proposed system can also overcome the light noise from other luminaries, i.e. sun-light, traffic-light, and so on. The simulation results show that the CDMA-based LED ranging system has a significant improvement for the ranging accuracy compared with the case without employing the CDMA.
\end{abstract}

Key Words : Ranging, LED, Visible light, CDMA, Time-of-Flight

\section{Introduction}

In the comprehensive report given by US Department of Transportation, a set of high potential beneficial safety applications, enabled by location estimation and vehicular communications, was identified $^{[1]}$. Thus, the usage of ranging device in vehicles is becoming common to improve the traffic safety.

Conventional methods, such as sonar, radar, LIDAR (light detection and ranging) and GPS have been taken into the consideration to measure the relative distance of the vehicles. Each of them has pros and cons in the aspects of cost, complexity and performance. Particularly, LED-based ranging appears as an alternative method, which performs low cost and complexity associated with the promise of high accuracy ${ }^{[2-4]}$.

This paper mainly focuses on the ranging accuracy of the vehicles based on LED lights transmission, and our purpose is to improve the accuracy for such a transmission to measure the relative distance of the vehicles. This is mainly because that the ranging cannot work with a high-rate errors on the desired ranging link. So, we propose an CDMA-based LED visible light ranging system, which combines the CDMA technique with an conventional ranging method i.e. time-of-flight $(\mathrm{TOF})^{[5-7]}$. The proposed algorithm can not only reduce the multi-user interference raised from adjacent vehicles but also overcome the noise which comes from other luminaries by using CDMA technology.

The remaining part of this paper is organized as follows. Section II presents the channel and system model. Our proposed algorithm is described in section III, and section IV shows the performance of the proposed scheme. Conclusions are given in section $\mathrm{V}$.

※ This work was supported by the IT \& R\&D program of SMBA.

- 주저자 : Department of Electronic Engineering, Inha University, cquptwy @126.com, 준회원

- 교신저자 : Department of Electronic Engineering, Inha University, khchang @inha.ac.kr, 종신회원

* Department of Electronic Engineering, Inha University, liang.cc@hotmail.com, 준회원, leosu8622@hotmail.com, 정회원 논문번호 : KICS2012-07-316, 접수일자 : 2012년 7월 11일, 최종논문접수일자 : 2012년 9월 28일 


\section{Channel Model for LED Optical Link}

In this section, we summarize an LED optical wireless channel model. In this optical link, the channel gain of LoS (line-of-sight) light path defined in [8] is given as:

$$
H(0)=\left\{\begin{array}{cr}
\frac{(m+1) A}{2 \pi D_{d}^{2}} \cos ^{m}(\phi) T_{s}(\psi) g(\psi) \cos (\psi), \\
0 \leq \psi \leq \Psi_{c} \\
0, & \psi>\Psi_{c}
\end{array}\right.
$$

where $A$ is the physical area of the detector in the photo-detector (PD), $D_{d}$ denotes the distance between a transmitter and a receiver, $\phi$ is the angle of irradiance, $\psi$ represents the angle of incidence, $T_{s}(\psi)$ is the gain of an optical filter, $g(\psi)$ is the gain of an optical concentrator, and $\Psi_{c}$ denotes the width of the field of vision at a receiver. The optical concentrator $g(\psi)$ can be given as:

$g(\psi)=\left\{\begin{array}{cl}\frac{n^{2}}{\sin ^{2} \Psi_{c}}, & 0 \leq \psi \leq \Psi_{c} \\ 0, & \psi>\Psi_{c}\end{array}\right.$

where $n$ is the refractive index.

Based on the directed light channel, the channel DC gain on reflected path is given as:

$$
d H_{r e f}(0)=\left\{\begin{array}{cr}
\frac{(m+1)}{2 \pi^{2} D_{1}^{2} D_{2}^{2}} \rho d A \cos ^{m}(\varphi) \cos (\alpha) & \\
\cdot \cos (\beta) T_{s}(\psi) g(\psi) \cos (\psi), & 0 \leq \psi \leq \bar{\psi}_{c} \\
0, & \psi \leq \bar{\psi}_{c}
\end{array}\right.
$$

where $D_{1}$ is the distance between an LED chip and a reflective point, $D_{2}$ is the distance between a reflective point and a receiver, $\rho$ is the reflectance factor (the power strength of the reflected signal compared with the original signal), $d A$ is a reflective area of small region, $\phi$ is the angle of irradiance to a reflective point, $\alpha$ is the angle of irradiance to a reflective point, $\beta$ is the angle of irradiance to the receiver, and $\psi$ is the angle of incidence as shown in Fig.1. Note that LED and PD are in a source vehicle (SV), which performs ranging operation.
Moreover, the received LED optical power is given by the transmitted LED optical power and the DC gain, which includes both directed and reflected paths as:

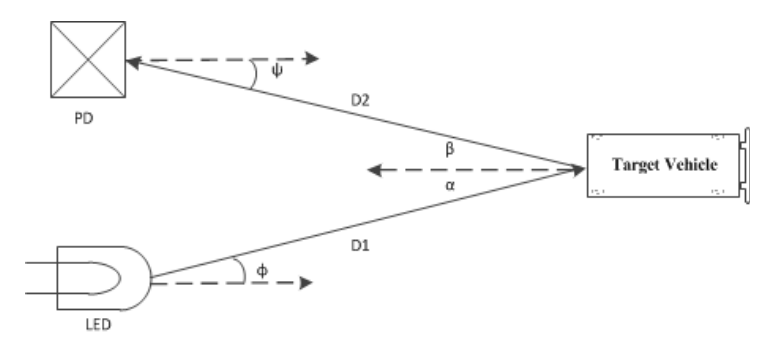

Fig . 1. Channel parameters of LED optical link.

$$
P_{r}=\sum^{L E D s}\left\{P_{t} H_{d}(0)+\int P_{t} d H_{r e f}(0)\right\}
$$

In this paper, we assume that the noise is an additive white Gaussian noise (AWGN). Accordingly, the LED optical wireless channel model can be expressed as:

$$
Y(t)=\gamma X(t) \otimes h(t)+N(t)
$$

where $Y(t)$ represents the received signal current, $\gamma$ is the detector responsivity that measures the input-output gain of a detector system, $X(t)$ denotes the transmitted optical pulse, $h(t)$ is the channel impulse response, and $N(t)$ represents the AWGN. The desired signal component $S$ then can be given by:

$S=\gamma^{2} P_{r \text { Signal }}^{2}$

where $P_{r \text { Signal }}$ is desired signal power calculated from beginning to time $T$ as:

$P_{\text {rSignal }}=\int_{0}^{T}\left(\sum_{i=1}^{L E D s} h_{i}(t) \otimes X(t)\right) d t$

The AWGN is the sum of contributions from shot noise and thermal noise denoted as:

$N=\sigma_{\text {shot }}^{2}+\sigma_{\text {thermal }}^{2}$ 
In the optical channels, the quality of transmission is typically dominated by shot noise, which is

$\sigma_{\text {shot }}^{2}=2 q \gamma\left(P_{r \text { Signal }}+P_{r I S I}\right) B+2 q I_{1} I_{2} B$

where $q$ is the electronic charge, $B$ is equivalent noise bandwidth, $I_{1}$ is background current. The noise bandwidth factors is defined as $I_{2} . P_{r I S I}$ is received power by intersymbol interference shown as:

$P_{r I S I}=\int_{T}^{\infty}\left(\sum_{i=1}^{L E D s} h_{i}(t) \otimes X(t)\right) d t$

The thermal noise variance is given by:

$\sigma_{\text {thermal }}^{2}=\frac{8 \pi k T_{k}}{G} \eta A I_{2} B^{2}+\frac{16 \pi^{2} k T_{k} \Gamma}{g_{m}} \eta^{2} A^{2} I_{3} B^{3}$

where those two terms represent feedback-resistor noise, and field effect transistor (FET) channel noise, respectively. Here, $k$ is Boltzmann's constant, $T_{k}$ is absolute temperature, $G$ is the open-loop voltage gain, $\eta$ is the fixed capacitance of photo detector per unit area, $\Gamma$ is the FET channel noise factor, $g_{m}$ is the FET transconductance, and the current $I_{3}=0.0868$.

\section{CDMA-based Time-of-flight Ranging}

In this paper, we deploy CDMA technology, which has been widely utilized to overcome multi-user interference, for LED-based ranging system. Thus, we combine CDMA technology with an efficient ranging algorithm, i.e. TOF for the verification of the proposed scheme.

In the algorithm of TOF, a LED light pulse (LLP) is generated. Then, it reaches the target and reflects back in a round-trip manner. Suppose $d$ is the distance to the target, $t$ is the echo time, and $c$ is the speed of light, then we have

$2 d=c \cdot t$

We should note that, for a non-ambiguous measurement, $t$ should be greater than the pulse width $T_{p}$ as :

$t>T_{p}$ or,

$d>\frac{1}{2} c T_{p}$

For example, let $T_{p}=10 \mathrm{ps}$, the minimum distance of ranging is $1.5 \mathrm{~m}$.

In the practical environment, the received LLP includes the reflected desired pulse and the interference pulses, where the intereference pulses may come from other neighbor ranging system. In order to obtain the desired LLP, we implement CDMA system based on TOF [5], [6], where the generated pseudo noise ( $\mathrm{PN}$ ) sequence can be the criterion to differentiate signals. Therefore, there are two major parts in the proposed system. The first is the ranging system which employes TOF, and the second is the verification system which employes CDMA to separate desired signal from others.

The proposed system block diagram is given by Fig.2. According to Fig.2, the generated bits in SV are spreaded by the PN sequence, in which the $\mathrm{M}$-sequence with the generation function (15) is suggested. Note, the M-sequence used for each vehicle can be distinguished by implementing different seed for (15).

$$
G(x)=x^{18}+x^{10}+x^{7}+x^{5}+1
$$

After spectrum spreading, the spreaded signal is modulated by LED light carrier. Note that the LLPs used for ranging are inserted in this procedure. Then, the signal is forwarded by SV, and reflected by the target vehicle (TV) which is located in front of the Tx vehicle via the LED optical link.

The receiver in the same SV may receive two kinds of signal, where one is desired ranging signal reflected by target vehicle, and the other is interference signal forwarded by neighbor vehicles. Thus, the receiver in SV cannot ranges the distance by an interfered received signal using TOF. In our proposed algorithm, the ranging system reserves the contaminated data, and then demodulate it to the baseband. The demodulated signal is despreaded by phase shifting the M-sequence. These despreaded sequences finally are used for verifying whether it is 
the desired ranging signal or interference signal. If the bits verification is done, the verification block gives a feedback to ranging system to pick up the desired ranging information.

There are several advantages improved by combining CDMA technology with the conventional TOF algorithm.

1) When the PN sequence is long enough, the target vehicles have less probability to be interfered forward error correction (FEC) is not implemented. Since a non-intense sunlight environment (during the night time) is assumed in the paper, we use the background light current of $5100 \mathrm{uA}$ for our simulation $^{[8]}$. Moreover, we do not consider the reflect area since we assume the signal can be received by source vehicle via one reflection of the target vehicle.

Fig.4 and Fig.5 show the bit error rate (BER) of

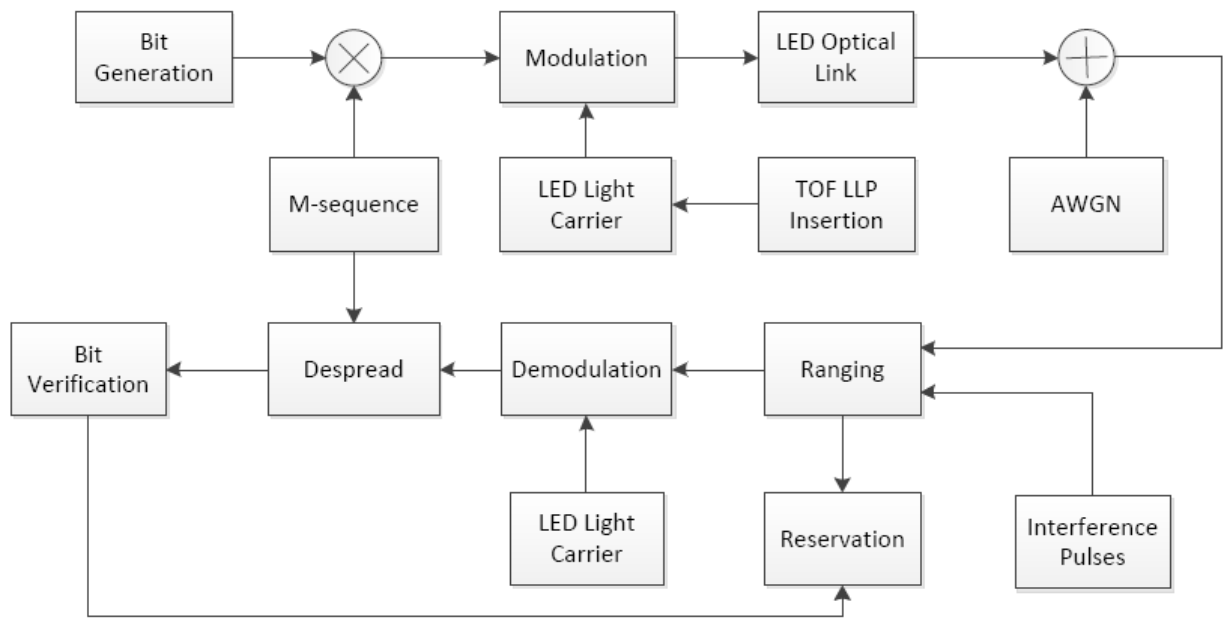

Fig. 2. Block diagram of the proposed LED-based ranging system.

by the neighbor interference vehicle (NIV).

2) Spread spectrum technique can also overcome the noise.

3) Compared with other schemes, less cost is required for our proposed algorithm due to use of the COTS (Common Off The Shelf) CDMA devices.

\section{Simulation Results}

To evaluate the link performance of the proposed CDMA-based ranging system, we investigate the simulation scenario as given in Fig.3, where three vehicles move in a same direction with which two of them are doing the ranging while the third one generates interference signal. Our simulation is mainly based on the specification of IEEE 802.15.7 [2], where the details of simulation parameters are given in Table 1. Of special note, we use the modulation of quadrature phase shift key (QPSK) instead of on-off keying (OOK) used in [2], and the ranging between the target vehicle and source vehicle of the cases without the CDMA and with the CDMA technique applied. Based on these two figures, we can observe that the ranging distance without any error is increased as the brightness

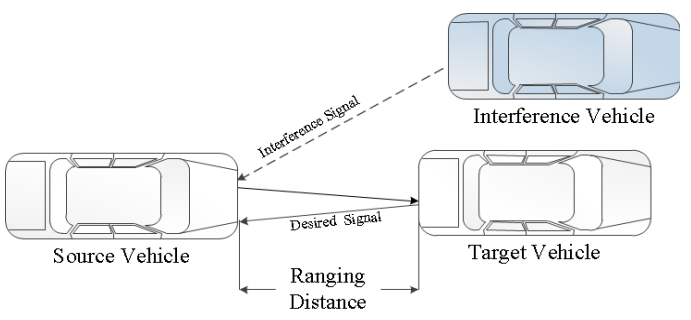

Fig. 3. Simulation Scenario.

Table 1. Simulation parameters.

\begin{tabular}{|c|c|}
\hline Parameters & Values \\
\hline Symbol Rate & $256 \mathrm{ksps}$ \\
\hline Modulation & QPSK \\
\hline M-sequence Seeds & TV: 011A0 \\
& NIV: $27 \mathrm{BFA}$ \\
\hline Detection Area $(S)$ & $7.8 * 10^{-5} \mathrm{~cm}^{2}$ \\
\hline
\end{tabular}




\begin{tabular}{|c|c|}
\hline Detector Responsitivity $(\gamma)$ & 0.55 \\
\hline Electronic Charge $(q)$ & 0.)^{*} 10^{-7}$ \\
\hline Noise Bandwidth Factors $\left(I_{2}\right)$ & 0.562 \\
\hline Open-loop Voltage Gain $(G)$ & 10 \\
\hline Fixed Capacitance $(\eta)$ & $112 \mathrm{pF} / \mathrm{cm}^{2}$ \\
\hline FET Channel Noise Factor $(\Gamma)$ & 1.5 \\
\hline FET Transconductance $\left(g_{m}\right)$ & $30 \mathrm{~ms}$ \\
\hline Absolute Temperature $\left(T_{k}\right)$ & $298 \mathrm{~K}$ \\
\hline Background Light Current $\left(I_{1}\right)$ & $5,100 \mathrm{uA}$ \\
\hline Reflectance Factor $(\rho)$ & 0.5 \\
\hline Nr. of Chips & 4 \\
\hline
\end{tabular}

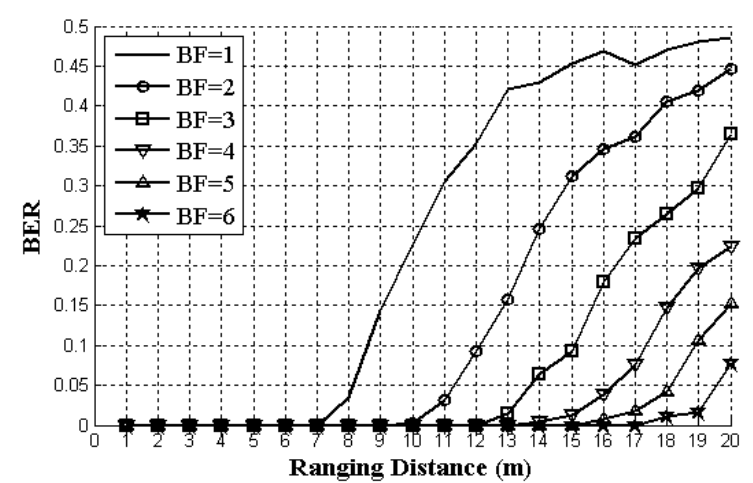

Fig. 4. Ranging distance vs. BER [without CDMA].

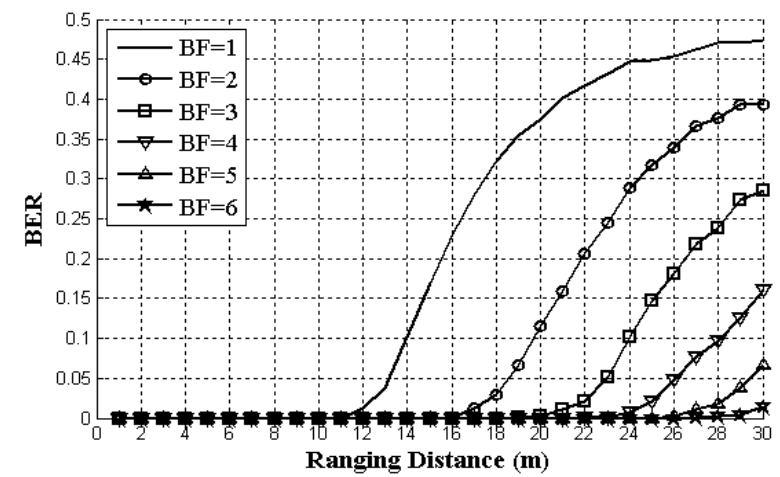

Fig 5. Ranging distance vs. BER [with CDMA].

factor (BF) grows up. However, the ranging distance with the CDMA used case have a significant improvement compared with the case without employing the CDMA at the same error probability. For example, the CDMA-based ranging distance in the case of $\mathrm{BF}$ equals 4 is increased from $13 \mathrm{~m}$ to $23 \mathrm{~m}$ at the error probability of 0 .

In Fig. 6 and Fig.7, we implement an interference vehicle, which provides the co-channel interference, and check the ranging accuracy in the source vehicle. In this simulation, we investigate scenario with the BF of 4 and ranging distance of $6 \mathrm{~m}$, where no errors occur in Fig.4 and Fig.5. In Fig.6 and Fig.7, however, due to the interference vehicle, link error occurs at the ranging distance of $6 \mathrm{~m}$, but it starts to be decreased as the interference distance varies from $6 \mathrm{~m}$. Fig.6 and Fig.7 give the variation of source vehicle BER in such an environment. According to Fig.6, the source vehicle BER starts

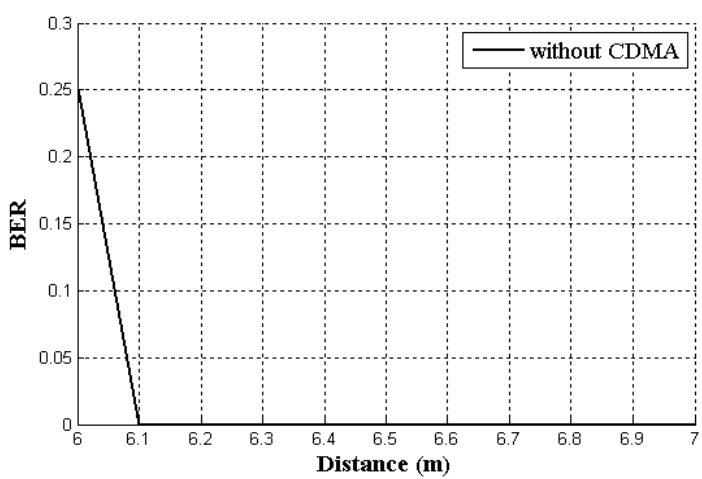

Fig. 6. Interference distance vs. BER [without CDMA].

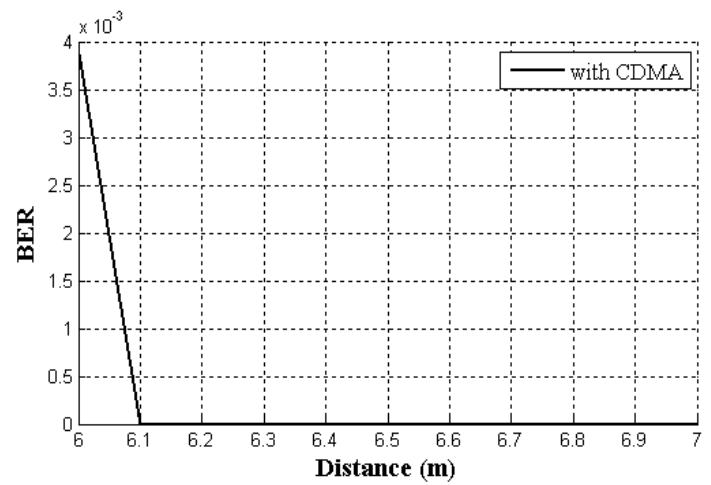

Fig .7. Interference distance vs. BER [with CDMA].

from 0.25 due to a strong co-channel interference introduced by the neighbor interference vehicle, and it goes to 0 because the co-channel interference is reduced as the distance increased. On the other hand, from Fig. 7 we notice that with the CDMA, the BER only starts from $4 * 10^{-3}$, which is almost sixty times smaller than the value in Fig. 5, and it also goes to 0 after the distance of $0.1 \mathrm{~m}$ between source vehicle and interference vehicle. 


\section{Conclusions}

This paper aims to investigate the ranging accuracy of an LED-based TOF ranging system. By using the CDMA technology, the ranging system can easily distinguish the desired ranging signal from the visible light interferences of the neighbor vehicles. Additionally, the ranging system can also overcome the light noise from other luminaries. The simulation results show that an accurate ranging with CDMA can extend the detection distance up to tens of meters, and the target signal error rate of the source vehicle can be decreased around sixty times even when a strong interference exists.

\section{References}

[1] R. Roberts, P. Gopalakrishnan, and S. Rathi, "Visible light positioning: automotive use case," in Proc. IEEE Vehicular Technology Conference 2010 (IEEE VTC-spring 2010), pp.1-6, Taipei, Taiwan, April 2010.

[2] S. Rajagopal, R. D. Robert and S. K. Lim, "IEEE 802.15.7 visible light communication : modulation schemes and dimming support," IEEE Comm. Magazine, vol. 50, no. 3, pp. 72-82, Mar. 2012.

[3] C. Kaiyun, C. Gang, and X. Zheng, "Line-of-sight visible light communication system design and demonstration" in Proc. Communication Systems, Networks and Digital Signal Processing 2010, (CSNDSP-2010), pp. 621-625, Newcastle, UK, July 2010.

[4] D. R. Kim, S. H. Yang, and Y. H. Son, "Line-of-sight visible light communication system design and demonstration" in Proc. Internaticnal Conference on Signal Processing and Communication Systems 2011 (ICSPCS-2011), pp. 1-7, Hawaii, US, Dec. 2011.

[5] J. S. Lee and L. E. Miller, CDMA Systems Engineering Handbook. $2^{\text {nd }}$ ED., Boston and London: Artech House Press, 2003.

[6] Siddharth Jain, Technical report on a survey of Laser Range Finding. pp. 1-14, Aug. 2003, from http://www-video.eecs.berkeley.

[7] C. C. Liang, Y. Wang, and K. H. Chang, "Fundamentals and applications of VLC on distance measurement," in Proc. KICS Summer Convergence Conference 2012 (KICS-summer 2012), pp. 603-604, Jeju Island, Korea, June 2012.

[8] T. Komine, and M. Nakagawa, "Fundamental analysis for visible-light communication system using LED lights," IEEE Trans. on on Consumer Electronics, vol.50, no.1, pp. 100-107, Feb. 2004.

\section{왕 양 (Yang Wang)}

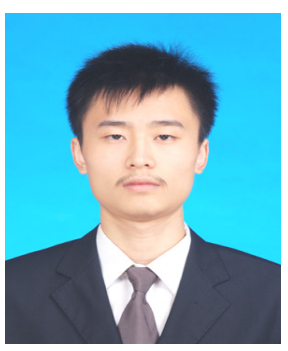

2010년 7월 중국 중경우전대 학교 통신공학과 공학사 2010년 8월 중국 중경우전대 학교 통신공학과 공학석사 과정 재학

2011년 8월 현재 인하대학교 전자공학과 교환학생

<관심분야> Visible Light Communication Systems,

Resource Management for Femtocells in LTE Network

\section{양 승 초 (Chengchao Liang)}

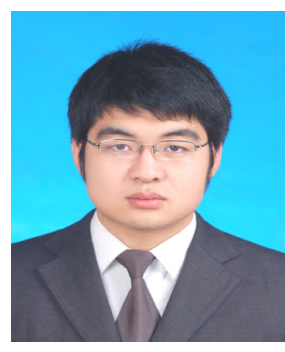

2010년 7월 중국 중경우전대 학교 통신공학과 공학사

2010년 8월 중국 중경우전대 학교 통신공학과 공학석사 과정 재학

2011년 8월 현재 인하대학교 전자공학과 교환학생

<관심분야> Visible Light Communication Systems, Resource Management for Femtocells in LTE Network 
소 신 $(\mathrm{Xin} \mathrm{Su})$

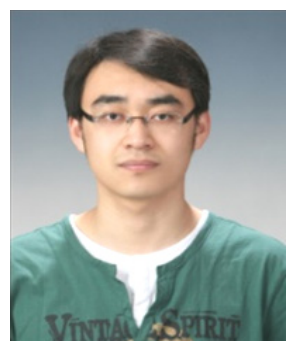

2008년 7월 중국 쿤민이공대

학교 컴퓨터공학과 공학사

2010년 8월 조선대학교 컴퓨

터공학과 공학석사

2011년 현재 인하대학교 정보

통신 대학원 박사과정

<관심분야> Mobile Ad-hoc

Network, Visible Light Communication Systems

\section{장 경 희 (KyungHi Chang)}

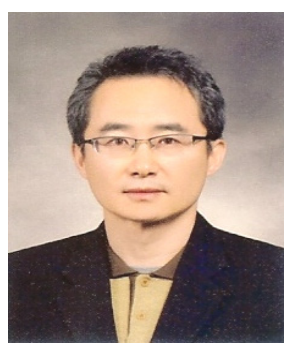

1985년 2월 연세대학교 전자 공학과 공학사

1987년 2월 연세대학교 전자공

학과 공학석사

1992년 8월 Texas A\&M

Univ., EE Dept. (Ph.D.)

원 주임연구원

1989년 1990년 삼성종합기술

1992년 2003년 한국전자통신연구원, 이동통신연구

소 무선전송방식연구팀장, 책임연구원

2003년 현재 인하대학교 전자공학과 교수

<관심분야> 3GPP LTE 및 WMAN 무선전송방식,

Corss-layer Design, Cooperative Relaying

System, Cognitive Radio, RFID/USN Systems,

Mobile Ad-hoc Network, 해상통신, 편파안테나

무선전송방식 등 